\title{
Design of Grooved Microstrip Patch Resonator Filters for Mobile Communication
}

\author{
Vivek Singh Kushwah ${ }^{1}$, Geetam Singh Tomar ${ }^{2}$ and Sarita Singh Bhadauria ${ }^{3}$ \\ Electronics and Communication Engineering Department \\ ${ }^{1}$ Amity University, Gwalior, INDIA \\ ${ }^{2}$ MIR Labs, Gwalior, India and THDC IHET Tehri \\ ${ }^{3}$ Madhav Institute of Technology \& Science, Gwalior, India \\ ${ }^{1}$ vivek_kushwah@rediffmail.com, ${ }^{2}$ gstomar@ieee.org, ${ }^{3}$ saritamits61@yahoo.co.in
}

\begin{abstract}
In advanced communication technology the microstrip filter has an important job in terms of selectivity and elimination of the undesired signals. In microwave and RF frequency applications the design of filter is complex task as lumped components cannot be used in this range of frequency. Microstrip filters are always preferred over the lumped filters at larger frequency for their compact size, lighter weight, lower cost and higher performance. In this paper the design of grooved microstrip patch resonator bandpass filter is presented at mid-band frequency $1.8 \mathrm{GHz}$ for L-Band applications. It also acts as a band-reject filter at center frequency $1.1 \mathrm{GHz}$, which is innovative concept in microstrip filter design. Band-pass filter has a high attenuation in stop band, small insertion loss of $0.5744 d B$ and high return loss of $26.52 d B$ in the pass band whereas Band-reject filter has a low attenuation, high insertion loss of $21.95 \mathrm{~dB}$ and low return loss of $0.2432 d B$ in the stop band. The result is encouraging and fabrication is also very easy.
\end{abstract}

Keywords: Band-pass filter, parallel cascaded grooved structure, Band-reject filter, Zeland IE3D EM Simulator

\section{Introduction}

In advanced communication system design consideration and size reduction has become major design parameters for practical applications. More efforts are being undertaken towards reducing the size of microwave components and devices, focusing especially on filters and antennas [1,2]. With the increasing demands towards miniaturization of size and for enhancing the performance of circuits, innovative techniques of making compact size microwave components and devices are used with better performance [22-24]. Low cost, sharp cut-off, compact size and insertion loss improvement are the main requirement for design of microstrip filters [6]. Filters are employed to smooth the communication and to choose the desired signal over other signals and noise. Microstrip filters are generally used in satellite and ground based communication systems. For designing such types of filters, various full wave electromagnetic simulators such as Zeland IE3D, Ansoft HFSS have been applied. The microstrip patch resonator has lower conductor losses and good power handling capabilities although it has slighter big size. In modern mobile communication systems narrowband filter with higher selectivity and higher performances have been widely used. The filter design is unique because it desires to be precise in terms of band width and cutoff ranges for the particular applications. Band pass filters are basically used end or parallel coupled microstrip line Sections [3,4]. These filters typically require several sections to have insertion loss of better than $3 \mathrm{~dB}$ [5]. Every section is divided by a gap which enhances the losses. Oppositely faced grooves would effect in lower loss, whereas 
deduction in the number of sections minimizes the probability of error in designing and fabricating of the filters. Such error may affect the performance of the microstrip filters. There have been numerous designs in practice and many researchers in the world are doing job to enhance the performance in terms of making sharp cutoff at band width edges, low cost, compact size, lowering insertion loss and improving return loss $[19,23$, 24]. This designed filter uses two adjacently opposite faced coupled half triangular tapered shaped microstrip patch resonators in a parallel cascaded geometry $[4,7,20]$.

\section{Related Work}

In [2] Aperture-Coupled Microstrip Open-Loop Resonators is proposed with their applications to the design of Novel Microstrip Bandpass Filters. A new filter configuration consists of two arrays of microstrip open-loop resonators, which can be coupled through the apertures on the common ground plane. Various filtering characteristics can easily be realized based on the apertures. In [4] a new method for implementation of bandpass microwave filters is proposed with poles of attenuation at ultimate frequencies. Necessary and sufficient conditions for the existence of transfer coefficient poles of a parallel connection of two four-port networks have been formulated. This filter has more advantage as compared to polynomial filters of a ladder-type structure. A compact bandpass filter design using symmetrically triangular open loop resonator is proposed in [7]. A new compact microstrip bandpass filter has been developed. The filter shows sharp rejection in the stop-band due to the three transmission zeros near the pass-band. A dual-mode bandpass filter using slot-line square loop resonator is proposed in [8]. Two types of slot patches are loaded in each corner to split the degenerate modes easily. For providing a large external coupling and source-load coupling, two T-shaped feed lines are used. The dual-mode filter has the advantages of relatively wideband and flexible transmission zeros to realize either symmetrical or asymmetrical suppression. A miniaturized high-order UWB bandpass filter using thirdorder E-shape microstrip structure is proposed in [9]. The responses of these miniaturized filters show one transmission zero at the upper stop-band. In [10] wideband microstrip bandpass filter based on quadruple mode ring resonator is proposed, which is developed by introducing a stepped-impedance one-wavelength ring resonator into a steppedimpedance half-wavelength resonator (SHR). Two band-stop sections with asymmetricaltype structure are introduced for suppressing the harmonic responses of the filter. Due to four transmission poles, the filter has low insertion loss and return loss with a small size. In [11] miniaturized UWB band pass filters are proposed with notch using slow-wave coplanar waveguide multiple-mode resonators. Stub-loaded microstrip CPW transitions are used to improve the upper rejection skirt of the UWB BPF, and the upper stop band rejection nearly $22 \mathrm{~dB}$ is obtained by using DGS units. In [12] a compact high selectivity seventh-order UWB bandpass filter is proposed with ultra-stopband attenuation, which is based on a unique E-shape microstrip structure and its equivalent circuit is developed for small wireless communication systems. The filter is composed of six grounded middle stub E-shape microstrip structures connected in cascade using short sections of the microstrip line. In [13] stepped-impedance coupled resonators (SICR) for implementation of parallel coupled microstrip filters are proposed with spurious band suppression. The SICR relies upon the incorporation of different stepped impedances for even and odd propagation modes of the coupled microstrip lines. In [14] a compact microstrip quintband filter based on the tri-mode stub-loaded stepped-impedance resonators is proposed. The design is more flexible and all passbands may be fully controlled by using multiple coupling paths. As a consequence, the advantages of flexible band control, highselectivity, and extremely small area make the newly proposed multi-band filters attractive and suitable for the applications in the multi-band communication systems. In [21] a microstrip wideband bandpass filter based on $\lambda / 2$ stub with spurious passband 
suppression scheme is proposed. In the design of bandpass filters, the use of half wavelength $(\lambda / 2)$ stubs of shunt configuration had been mostly unacceptable due to their effect of narrow stopband bandwidths in the resulting filters. The designed filter reported to have low insertion loss nearly $-1.98 \mathrm{~dB}$ and a fractional bandwidth of $50 \%$ at $6 \mathrm{GHz}$ mid-band frequency. The filter is planar, fabricated on FR-4 substrate which makes it cost-effective. In [22] a new design of parallel grooved band-pass resonator filter is proposed at $4.25 \mathrm{GHz}$. This filter has a high attenuation in stop band, high return loss and small insertion loss in the pass band. In [23], [24] ANN modeling for various filters is proposed for improving the performance, size, losses and cost. In [25] a novel concept of microstrip low pass filter is presented with Defected Ground Structure for minimizing the losses and size.

\section{Proposed Grooved Microstrip Filter}

The filter design was performed using the Zeland IE3D 14.1 full wave Electromagnetic simulator. The length and width of microsrip filter is chosen for the frequency band beyond $1.1 \mathrm{GHz}$ and is illustrated in figure 1.The operating frequency depends on the curves obtained after the EM simulation and is given by

$$
\mathrm{f}=\left(\frac{0.57 c}{h L \sqrt{\varepsilon r}}\right) \mathrm{Hz}
$$

Where $\mathrm{c}$ is the speed of light which is equal to $3 \times 10^{11} \mathrm{~mm} / \mathrm{sec}$., $\varepsilon_{\mathrm{r}}$ is the dielectric constant of the substrate, $\mathrm{h}$ is the thickness of the substrate in $\mathrm{mm}$. the operating frequency $\mathrm{f}$ is in Hertz and $\mathrm{L}$ is length in millimeter. The width $\mathrm{W}$ is in millimeter and is selected to provide the better return loss in the pass band and higher attenuation in the stop band. The length $\mathrm{L}$ is calculated using the equation (1) and is equal to $28.31 \mathrm{~mm}$. and width $\mathrm{W}$ is given by $\mathrm{W}=45.28 \mathrm{~mm}$ generally chosen as 1.6 times of $\mathrm{L}$.

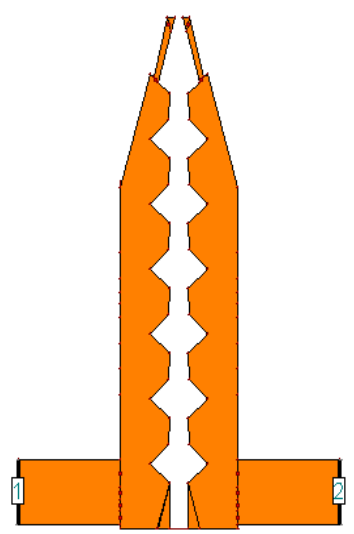

Figure 1. Layout of a Grooved Microstrip Band Pass Resonator Filter on Fr4 Substrate with Gap

The Gap between the two coupled structures is kept almost equal to $4 \mathrm{~mm}$. In this filter design the number of grooves should be taken six. Groove depth is of $3.7 \mathrm{~mm}$ at maximum taper and groove length is of order of $3.7 \mathrm{~mm}$. The distance between two adjacent grooves should be kept at $2.8 \mathrm{~mm}$. Grooves provide the better coupling of signal at the required signal spectrum. This ratio provides the best return loss Characteristics. Equation (1) determines all of the filter's dimensions. These dimensions should produce a filter with an insertion loss of around $0.5744 \mathrm{~dB}$ in the passband and good attenuation in stop band up to the maximum of $21.95 \mathrm{~dB}$. The thickness of the substrate $(\mathrm{h})$ has the little effect on the filter's operating frequency, but on the other side it plays a very important role in determining the filter's bandwidth. The attenuation at $1.8 \mathrm{GHz}$ is around $0.5 \mathrm{~dB}$. Changes 
in dielectric constant greatly affect the operating frequency unlike of the substrate thickness. Since changing the dielectric constant changes the operating frequency, different $\mathrm{W}$ and $\mathrm{L}$ determined by the equation (1) is used for each filter to work at the required frequency. Bandwidth available is of $1 \mathrm{GHz}$ and percentage bandwidth of $20 \%$. The design parameters for the design are chosen in such a manner that it does not have any matching problem when it is put to use with the other microwave devices like transmission equipment and antenna matching unit [18]. The impedance of design is adjusted at $50 \mathrm{ohm}$ and does not have any variation during various test carried out for performance evaluation. IE3D Layout of the grooved microstrip band pass filter with gap is shown in Figure 1 and layout of the grooved microstrip band pass filter without gap is shown in Figure 2. The 3Dimensional view of the grooved microstrip band pass filter without gap is shown in Figure 3.

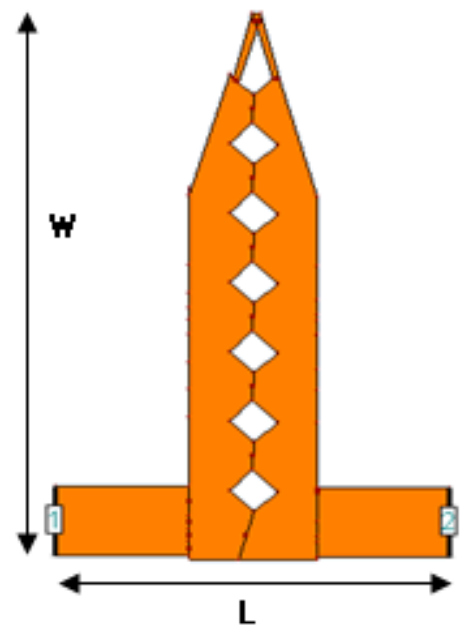

Figure 2. Layout of a Grooved Microstrip Band Pass Filter on Fr4 Substrate without Gap

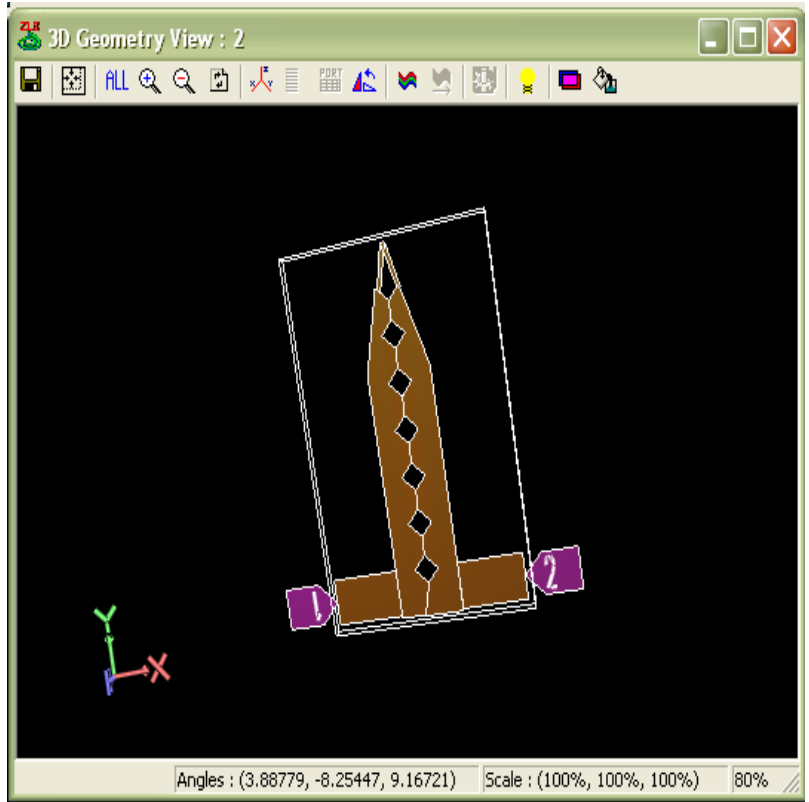

Figure 3. 3-D Geometry of a Grooved Microstrip Band Pass Filter

EM simulated performance of the grooved microstrip patch resonator bandpass filter is shown in Figure 4 and 5. Figure 4 represents the magnitude variation characteristics and 
figure 5 represents the phase variation characteristics of the grooved microstrip band pass filter with respect to frequency.

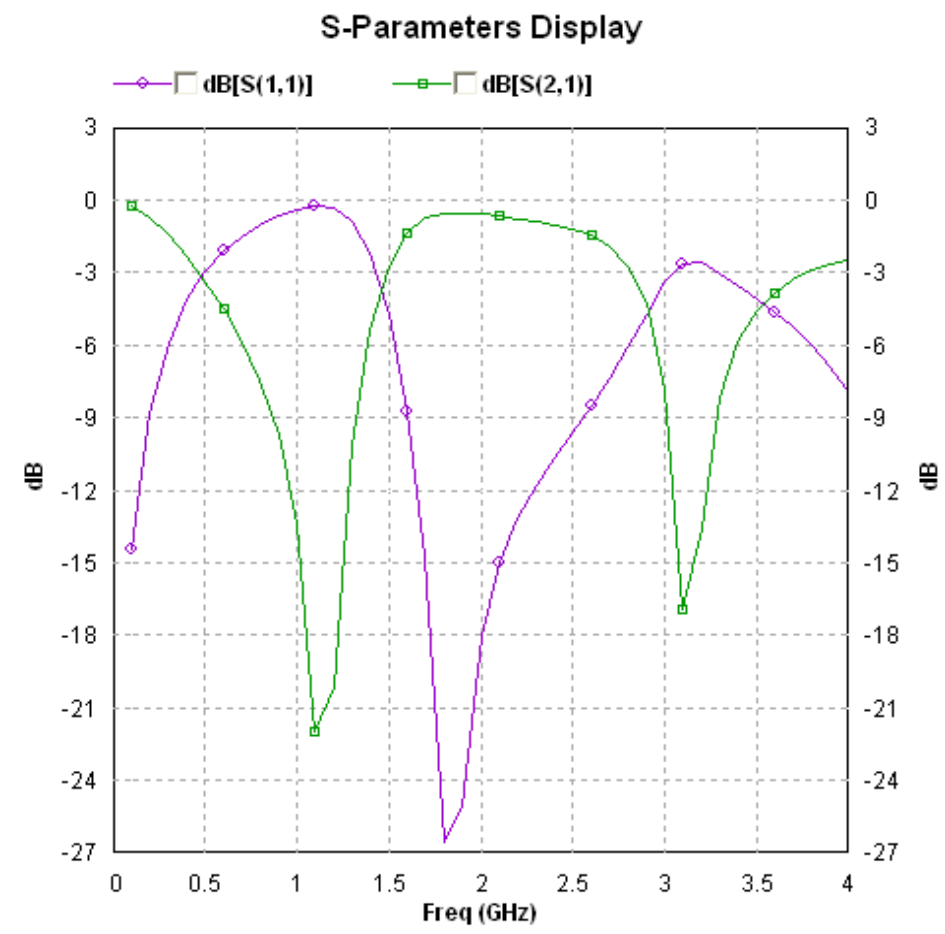

Figure 4. Magnitude Response of a Grooved Microstrip Band Pass Filter at $1.8 \mathrm{GHz}$

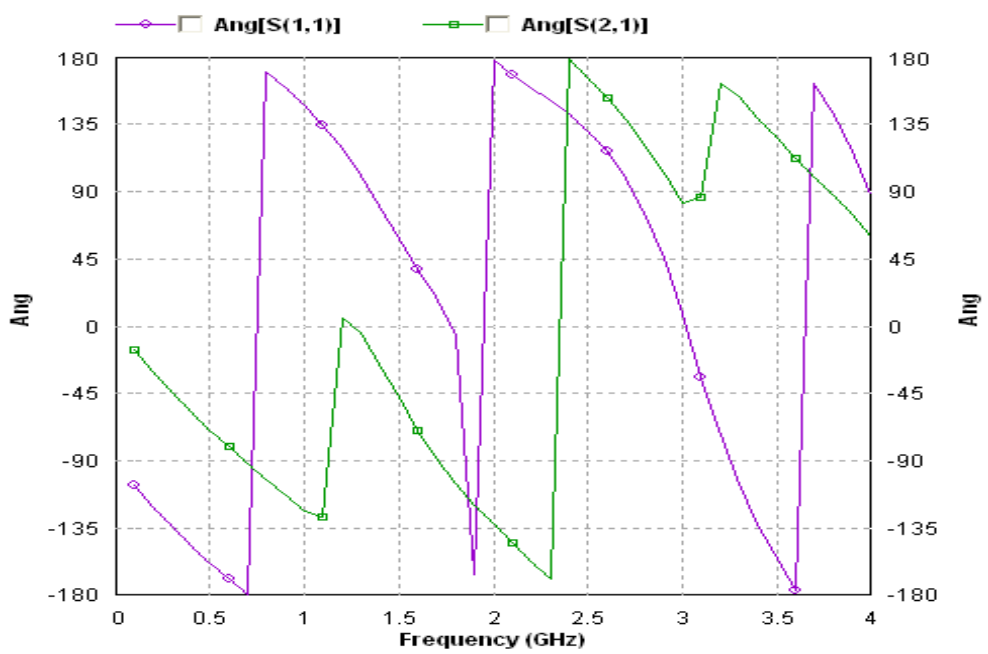

\section{Figure 5. Phase response of a Grooved Microstrip Band Pass Filter at 1.8 $\mathrm{GHz}$}

Figure 6 and Figure 7 represents the fabricated grooved microstrip resonator band pass filter in horizontal and vertical measurement scale. The measured response of the filter is achieved with the help of FS-315 Spectrum analyzer as shown in Figure 8, which represent the maximum attenuation of $25 \mathrm{~dB}$ in the stop-band. The total cross sectional area of the grooved microstrip filter is $(28.31 \times 45.28) \mathrm{mm}^{2}$ which is more compact as compared to previous designs $[21,23]$. 


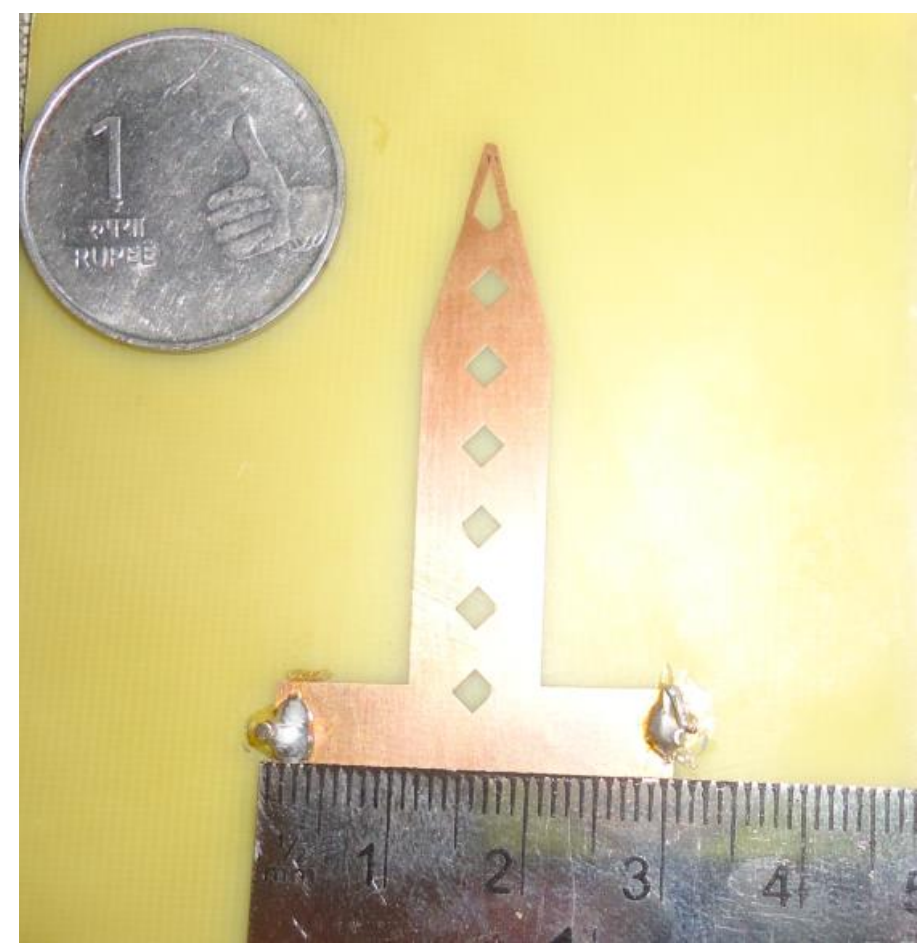

Figure 6. Fabricated Prototype of Grooved Microstrip Band Pass Resonator Filter on FR4 Substrate (Horizontal Measurement)

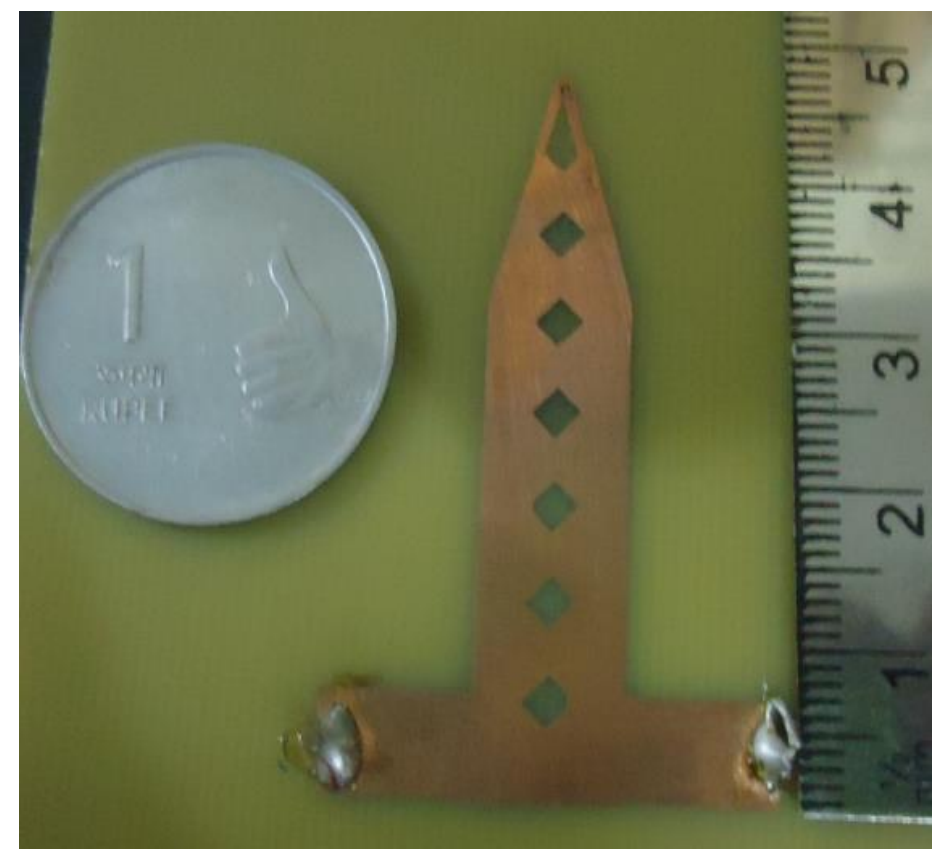

Figure 7. Layout of Fabricated Grooved Microstrip Band Pass Resonator Filter on FR4 Substrate (Vertical Measurement)

Figure 8 and Table 1 represent the comparison between measured and simulated $S_{21-}$ parameters. It represents the comparative performance graph of measured and simulated insertion loss for grooved microstrip patch resonator band pass filter. Simulated performance represents the maximum attenuation of $21.95 \mathrm{~dB}$ in the stop-band and measured response indicates the improved maximum attenuation of $24.9 \mathrm{~dB}$ in the stopband. 
Table 1. Comparison of Measured and Simulated Results for $\mathbf{S}_{\mathbf{2 1}}$

\begin{tabular}{|c|c|c|}
\hline Frequency $f$ in $\mathrm{GHz}$ & Measured S21 & Simulated $S_{21}$ \\
\hline 0.1 & -0.4 & -0.2213 \\
\hline 0.2 & -1 & -0.7123 \\
\hline 0.3 & -1.9 & -1.434 \\
\hline 0.4 & -3.5 & -2.326 \\
\hline 0.5 & -4.5 & -3.35 \\
\hline 0.6 & -5.2 & -4.509 \\
\hline 0.7 & -6.9 & -5.85 \\
\hline 0.8 & -8.6 & -7.499 \\
\hline 0.9 & -10.9 & -9.745 \\
\hline 1 & -14.6 & -13.37 \\
\hline 1.1 & -24.9 & -21.95 \\
\hline 1.2 & -21.99 & -20.11 \\
\hline 1.3 & -11.7 & -10.22 \\
\hline 1.4 & -6.5 & -5.409 \\
\hline 1.5 & -3.8 & -2.711 \\
\hline 1.6 & -1.5 & -1.348 \\
\hline 1.7 & -0.9 & -0.767 \\
\hline 1.8 & -0.7 & -0.5744 \\
\hline 1.9 & -0.678 & -0.5535 \\
\hline 2 & -1.04 & -0.6029 \\
\hline 2.1 & -1.12 & -0.6814 \\
\hline 2.2 & -0.9989 & -0.7766 \\
\hline 2.3 & -1.2771 & -0.8899 \\
\hline 2.4 & -1.342 & -1.031 \\
\hline 2.5 & -1.435 & -1.219 \\
\hline 2.6 & -1.675 & -1.49 \\
\hline 2.7 & -2.564 & -1.921 \\
\hline 2.8 & -3.234 & -2.696 \\
\hline 2.9 & -5.278 & -4.278 \\
\hline 3 & -8.567 & -7.899 \\
\hline 3.1 & -19.976 & -16.96 \\
\hline 3.2 & -14.675 & -13.59 \\
\hline 3.3 & -10.234 & -8.153 \\
\hline 3.4 & -6.987 & -5.834 \\
\hline 3.5 & -5.675 & -4.602 \\
\hline 3.6 & -4.876 & -3.833 \\
\hline 3.7 & -4.286 & -3.295 \\
\hline 3.8 & -3.564 & -2.897 \\
\hline 3.9 & -3.9 & -2.616 \\
\hline 4 & -3.7 & -2.469 \\
\hline
\end{tabular}


Table 2. Comparison of Return- loss $\left(\mathbf{S}_{11}\right)$

\begin{tabular}{|c|c|c|}
\hline Frequency $f$ in GHz & Measured $\mathrm{S}_{11}$ & Simulated $S_{11}$ \\
\hline 0.1 & -15.64 & -14.44 \\
\hline 0.2 & -9.842 & -8.842 \\
\hline 0.3 & -6.902 & -5.922 \\
\hline 0.4 & -4.93 & -4.13 \\
\hline 0.5 & -3.674 & -2.94 \\
\hline 0.6 & -3.115 & -2.106 \\
\hline 0.7 & -2.496 & -1.493 \\
\hline 0.8 & -2.026 & -1.023 \\
\hline 0.9 & -1.8874 & -0.6573 \\
\hline 1 & -0.3868 & -0.3868 \\
\hline 1.1 & -0.3456 & -0.2432 \\
\hline 1.2 & -0.3999 & -0.3286 \\
\hline 1.3 & -0.9633 & -0.8644 \\
\hline 1.4 & -2.871 & -2.21 \\
\hline 1.5 & -4.993 & -4.743 \\
\hline 1.6 & -9.729 & -8.728 \\
\hline 1.7 & -15.79 & -14.73 \\
\hline 1.8 & -28.82 & -26.52 \\
\hline 1.9 & -26.14 & -25.14 \\
\hline 2 & -19.565 & -18.05 \\
\hline 2.1 & -17.31 & -15.01 \\
\hline 2.2 & -14.76 & -13.16 \\
\hline 2.3 & -12.83 & -11.81 \\
\hline 2.4 & -11.99 & -10.66 \\
\hline 2.5 & -10.596 & -9.596 \\
\hline 2.6 & -9.896 & -8.526 \\
\hline 2.7 & -8.899 & -7.389 \\
\hline 2.8 & -7.625 & -6.123 \\
\hline 2.9 & -5.456 & -4.72 \\
\hline 3 & -4 & -3.393 \\
\hline 3.1 & -2.689 & -2.621 \\
\hline 3.2 & -2.698 & -2.607 \\
\hline 3.3 & -3.987 & -3.017 \\
\hline 3.4 & -3.567 & -3.535 \\
\hline 3.5 & -4.768 & -4.065 \\
\hline 3.6 & -4.678 & -4.624 \\
\hline 3.7 & -5.097 & -5.261 \\
\hline 3.8 & -6.56 & -6.024 \\
\hline 3.9 & -7.008 & -6.928 \\
\hline 4 & -7.989 & -7.88 \\
\hline
\end{tabular}




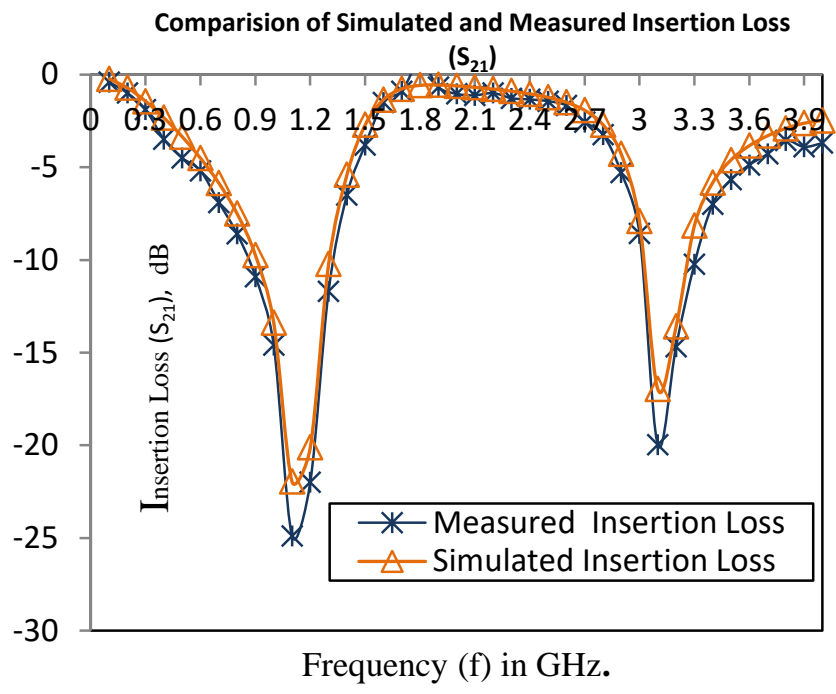

Figure 8. Comparison of Measured and Simulated Insertion Loss of a Grooved Microstrip Band Pass Filter

Figure 9 and Table 2 represent the comparison between measured and simulated $\mathrm{S}_{11^{-}}$ parameters of microstrip filter. It represents the comparative performance graph of measured and simulated return loss for grooved microstrip patch resonator band pass filter. Simulated performance represents the maximum return loss of $26.52 \mathrm{~dB}$ in the passband and measured response indicates the improved maximum return loss of $28.82 \mathrm{~dB}$ in the pass-band as shown in Figure 9. Both simulated and measured results are matched well for the desired frequency band. Impedance matching properties of grooved microstrip filter can be explained well with the help of smith chart as illustrated in Figure 10 , which represent the nature of impedance i.e., inductive, capacitive or purely resistive.

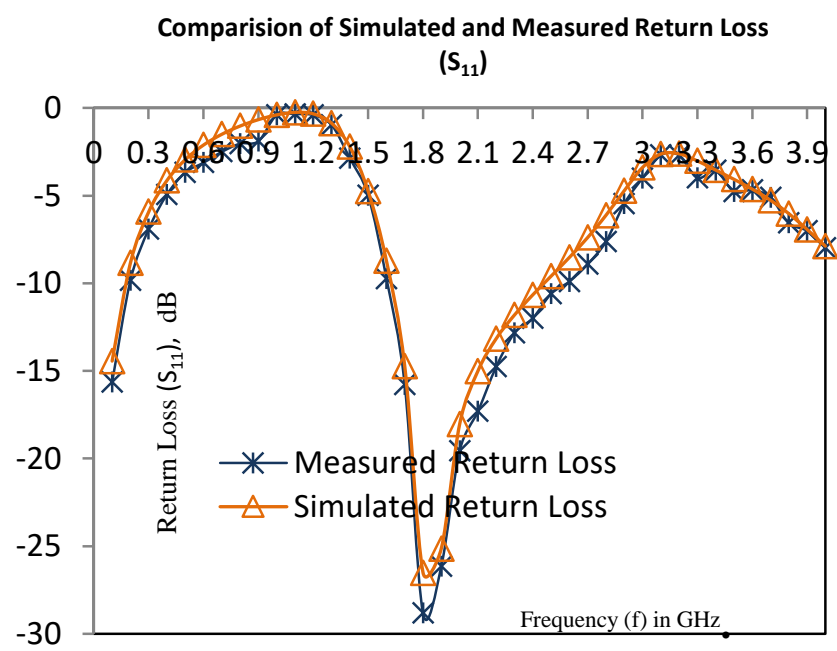

Figure 9. Comparison of Measured and Simulated Return Loss $\left(S_{11}\right)$ of Grooved Microstrip Band Pass Filter 


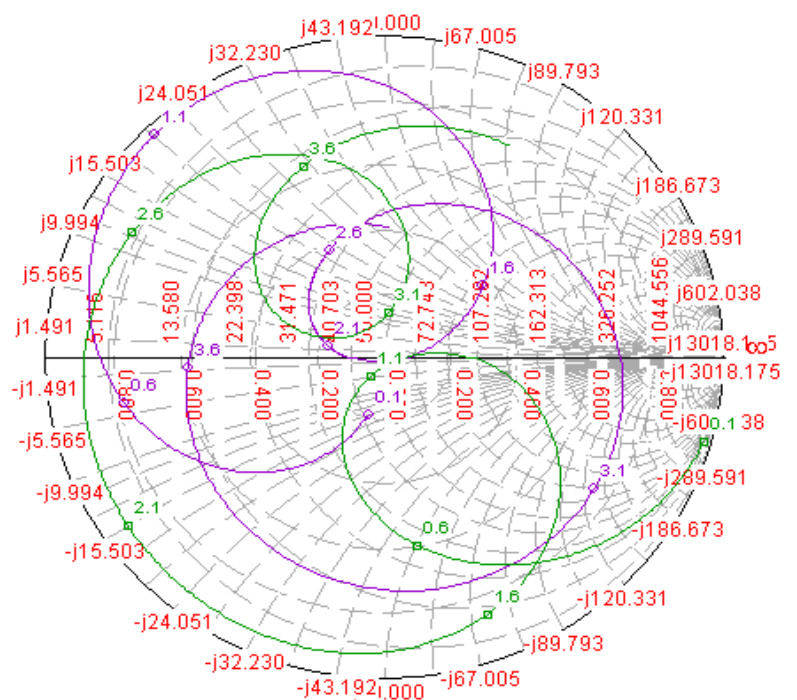

Figure 10. Smith Chart for Grooved Microstrip filter

\section{Results and Filter Performance}

The design of filter has given good results especially in terms of insertion loss, it has given good results. The major performance parameters i.e., insertion loss and return loss is plotted in Figure 4. IE3D analysis for changes in the filter's dimensions and substrate dielectric constant was carried at different frequencies. IE3D proved the effectiveness of the design equation at this frequency. The layout of the filter is given in Figure 2 and the simulated response is given in Figure 4 and 5. Measured response is achieved with the help of FS-315 Spectrum analyzer as illustrated in Figure 8 and 9 which gives the comparison of measured and simulated results. The value of width $\mathrm{W}$ chosen should be at least 1.6 times more than the value of length $L$ for the satisfactory performance of the filter.

Figure 4 and 5 shows the simulated S-parameter curves for a filter with total length (L) $=28.31 \mathrm{~mm}$ and total width $(\mathrm{W})=45.28 \mathrm{~mm}, \mathrm{Gap}=0 \mathrm{~mm}$. The commercial dielectric substrate FR4 is used which has thickness of $1.6 \mathrm{~mm}$ and dielectric constant of 4.4.Measured results shows the improved performance of the filter and maximum attenuation of $25 \mathrm{~dB}$ in stop-band. Both measured and simulated results are matched well. Bandwidth available is of $1 \mathrm{GHz}$ and percentage bandwidth of 20. IE3D version 14.1 simulation accurately judge the performance of filter. The advantage of this filter is of having desired performance, low losses and compact size.

\section{Conclusion}

Grooved microstrip filter represents the dual nature of filter. A grooved Band-pass filter has been proposed at mid band frequency $1.8 \mathrm{GHz}$ with very compact size, higher performance, lighter weight and lower cost for L-band applications such as mobile (GSM) and satellite communication. It has low loss in the pass band and maximum attenuation in the stop band. Band-pass filter has small insertion loss of $0.5744 \mathrm{~dB}$ and high return loss of $26.52 \mathrm{~dB}$ in the pass band. The behavior of this filter is different at different frequency band. It behaves like a band-reject filter at center frequency $1.1 \mathrm{GHz}$. It has a low attenuation, high insertion loss of $21.95 \mathrm{~dB}$ and low return loss of $0.2432 \mathrm{~dB}$ in the stop band This filter can be easily fabricated. The filter characteristics also offer a very useful margin for microwave applications. 


\section{References}

[1] J. Shen, G. Hong \& M. J. Lancaster, "Microstrip Filters for RF/Microwave Applications”, John Wiley \& Sons Inc., (2001).

[2] J. S. Hong and M. J. Lancaster, "Aperture-Coupled Microstrip Open-Loop Resonators and Their Applications to the Design of Novel Microstrip Bandpass Filters", IEEE Transactions of Microwave Theory \& Techniques, vol. 47, issue 9, no.2, (1999), pp. 1938-1948.

[3] G. I. Mathai, L Young and E. M. T. Jones, "Microwave filters, impedance matching and and coupling structures", McGraw-Hill, Newyork, (1964).

[4] V. Osipenkov and S. Vesnin, "Microwave filters of parallel cascade structure", IEEE Transactions of Microwave Theory \& Techniques, vol. 42, (1994), pp. 1360-1367.

[5] J. S. Hong and M. J. Lancaster, "Design of Highly Selective Microstrip triangular patch resonator filters", IEEE Transactions of Microwave Theory \& Techniques, vol. 1, (2000), pp. 331-334.

[6] J. S. Hong and M. J. Lancaster, "Recent progress in planar microwave filters", IEEE 3rd International Conference on Microwave and Millimeter Wave Technology, (2002), pp. 1134-1137.

[7] C. G. Sun, H. X. Zheng and L. Y. Feng, "A Compact Bandpass Filter Design Using Symmetrically Triangular Open Loop Resonator", IEEE 2nd International Conference on Consumer Electronics, Communications and Networks (CECNet), (2012), pp. $17-20$.

[8] B. Wu, W. Su, S. J. Sun, C. H. Liang, "Novel Dual-Mode Bandpass Filter Using Slot-Line Square Loop Resonator", IEEE International Conference on Microwave and Millimeter Wave Technology (ICMMT), vol. 2, (2012), pp.1-3.

[9] R. T. Hammed and D. M. Syahkal, "Miniaturized High-Order UWB Bandpass Filter Using Third-Order E-Shape Microstrip Structure", IEEE MTT-S International Microwave Symposium Digest (MTT), (2012), pp. 1 - 3.

[10] J. Fan, D. Zhan, C. Jin, and J. Luo, "Wideband Microstrip Bandpass Filter Based on Quadruple Mode Ring Resonator", IEEE Microwave and Wireless Components Letters, vol. 22, iss. 7, (2012), pp. 348 350.

[11] V. Sekar and K. Entesari, "Miniaturized UWB Bandpass Filters With Notch Using Slow-Wave CPW Multiple-Mode Resonators", IEEE Microwave and Wireless Components Letters, vol. 21, iss. 2, (2011), pp. 80-82.

[12] R. T. Hammed and D. M. Syahkal, "A Compact High Selectivity Seventh-Order UWB Bandpass Filter With Ultra-Stopband Attenuation”, IEEE Radio and Wireless Symposium (RWS), (2012), pp. 135 138.

[13] A. Worapishet, K. Srisathit and W. Surakampontorn, "Stepped-Impedance Coupled Resonators for Implementation of Parallel Coupled Microstrip filters With Spurious Band Suppression", IEEE Transactions on Microwave Theory \& Techniques, vol. 60, iss. 6, (2012), pp. 1540-1548.

[14] C. F. Chen, "Design of a Compact Microstrip Quint-Band Filter Based on the Tri-Mode Stub-Loaded Stepped-Impedance Resonators", IEEE Microwave and Wireless Components Letters, vol. 22 , iss. 7, (2012), pp. $357-359$.

[15] S. Shi, W. W. Choi, W. Che, K. W. Tam and Q. Xue, "Ultra-Wideband Differential Bandpass Filter With Narrow Notched Band and Improved Common-Mode Suppression by DGS", IEEE Microwave and Wireless Components Letters, vol. 22 , iss. 4, (2012), pp.185- 187.

[16] F. Cheng, X. Lin, Y. Hu and Yong Fan, "Tunable Bandpass Filter using Varactor-Loaded QuarterWavelength Resonator", IEEE International Conference on Microwave and Millimeter Wave Technology (ICMMT), vol. 5, (2012), pp. 1-3.

[17] T. W. Lin, J. T. Kuo and S. J. Chung, "Dual-Mode Ring Resonator Bandpass Filter With Asymmetric Inductive Coupling and Its Miniaturization", IEEE Transactions on Microwave Theory \& Techniques, vol. 60, iss. 9, (2012), pp. 2808-2814.

[18] W. J. Feng, W. Q. Che and Q. Xue, "Novel Dual-band Band-pass Filter Using Multi-mode Resonator", IEEE 4th International Conference on High Speed Intelligent Communication Forum (HSIC), (2012), pp. $1-4$.

[19] R. E. Zich, M. Mussetta, F. Grimaccia, A. Gandelli, H. M. Linh, G. Agoletti, M. Bertarini, L. Combi, P. F. Scaramuzzino and A. Serboli , "Comparison of different optimization techniques in microstrip filter design", IEEE Asia-Pacific International Microwave Symposium on Electromagnetic Compatibility (APEMC), (2012), pp. 549-552.

[20] M. Meng, I. C. Hunter, "The design of parallel connected filter networks with non-uniform Q resonators", IEEE MTT-S International Microwave Symposium Digest (MTT), (2012), pp. 1 - 3.

[21] P. Chakravorty, "A microstrip wideband bandpass filter based on $\lambda / 2$ stub with spurious passband suppression scheme", International Journal of Electronics, Taylor \& Francis, (2013), pp. 37-41.

[22] V. S. Kushwah, S. S. Tomar and S. Sharma, "Design of Grooved Microstrip Band-Pass Filter at 4.25 GHz", Fourth IEEE International Conference on Communication Systems and Network Technologies, CSNT 2014, (2014), pp. 49-53.

[23] G. S. Tomar, V. S. Kushwah and S. S. Bhadauria, "Artificial Neural Network Design of Stub Microstrip Band-pass Filters", International Journal of Ultra wideband Communication Systems, Inderscience publishers, vol. 3, no.1, (2014), pp. 38-49. 
International Journal of Future Generation Communication and Networking

Vol. 9, No. 5 (2016)

[24] V. S. Kushwah, A. S. Tomar, "ANN Modeling of Microstrip Hairpin-Line Bandpass Filter", International Journal of Communication Systems and Network Technologies, ISSN 2053-6283, vol. 3, no. 1, (2014), pp. 58-64.

[25] V. S. Kushwah, S. S. Bhadauria and G. S. Tomar, "Design of Microstrip Low pass filter with Defected Ground Structure," IEEE International Conference on Computational Intelligence and Communication Networks, (2015), pp. 12-15. 